\title{
Komagataeibacter rhaeticus as an alternative bacteria for cellulose production
}

\author{
Rachel T.A. Machado ${ }^{a}$, Junkal Gutierrez ${ }^{b}$, Agnieszka Tercjak $^{\text {b }}$, Eliane Trovatti ${ }^{\text {a }}$, \\ Fernanda G.M. Uahib ${ }^{c}$, Gabriela de Padua Moreno ${ }^{c}$, Andresa P. Nascimento ${ }^{c}$, \\ Andresa A. Berreta ${ }^{c}$, Sidney J.L. Ribeiro ${ }^{\mathrm{d}}$, Hernane S. Barud ${ }^{\mathrm{a}, \mathrm{d}, *}$

\footnotetext{
a Laboratório de Biopolimeros e Biomateriais (BIOPOLMAT), Centro Universitário de Araraquara, Araraquara, 14801-340 São Paulo, Brazil

b Group 'Materials + Technologies' (GMT), Department of Chemical and Environmental Engineering, Engineering College of Gipuzkoa, University of the Basque Country (UPV/EHU), Plaza Europa 1, 20018 Donostia-San Sebastián, Spain

' Laboratório de Pesquisa, Desenvolvimento E Inovação, Apis Flora Ind. Coml. Ltda, Ribeirão Preto, 14020-670 São Paulo, Brazil

${ }^{\mathrm{d}}$ Institute of Chemistry-São Paulo StateUniversity-UNESP, 14800-060 Araraquara-SP, Brazil
}

\section{A R T I C L E I N F O}

\section{Article history:}

Received 15 March 2016

Received in revised form 5 June 2016

Accepted 12 June 2016

Available online 15 June 2016

\section{Keywords:}

Bacterial cellulose

Komagataeibacter rhaeticus

Cellulose production

3D network structure

Mechanical properties

\begin{abstract}
A B S T R A C T
A strain isolated from Kombucha tea was isolated and used as an alternative bacterium for the biosynthesis of bacterial cellulose (BC). In this study, BC generated by this novel bacterium was compared to Gluconacetobacter xylinus biosynthesized BC. Kinetic studies reveal that Komagataeibacter rhaeticus was a viable bacterium to produce $\mathrm{BC}$ according to yield, thickness and water holding capacity data.

Physicochemical properties of $\mathrm{BC}$ membranes were investigated by UV-vis and Fourier transform infrared spectroscopies (FTIR), thermogravimetrical analysis (TGA) and X-ray diffraction (XRD). Additionally, scanning electron microscopy (SEM) and atomic force microscopy (AFM) were also used for morphological characterization. Mechanical properties at nano and macroscale were studied employing PeakForce quantitative nanomechanical property mapping (QNM) and dynamic mechanical analyzer (DMA), respectively.

Results confirmed that $\mathrm{BC}$ membrane biosynthesized by Komagataeibacter rhaeticus had similar physicochemical, morphological and mechanical properties than BC membrane produced by Gluconacetobacter xylinus and can be widely used for the same applications.
\end{abstract}

(c) 2016 Elsevier Ltd. All rights reserved.

\section{Introduction}

Bacterial cellulose (BC) is a special type of nanocellulose produced by microorganisms which has been deeply studied, mainly in terms of biosynthesis and applications since its discovery in 1886 (Brown, 1886). BC is produced by different type of bacteria such as Gluconacetobacter, Rhizobium, Agrobacterium, Aerobacter, Achromobacter, Azotobacter, Sarcina and Salmonella (Lustri et al., 2015; Shoda \& Sugano, 2005), among others. The most attractive genus from a commercial point of view is Gluconacetobacter due to this ability to produce large amounts of cellulose (Trovatti et al., 2013; Trovatti, 2013).

Cellulose fiber consists of long polymer chains of D-glucose joined by $\alpha-1,4$ glycosidic bonds. The macromolecules chains are

\footnotetext{
* Corresponding author at: Laboratório de Biopolimeros e Biomateriais (BIOPOLMAT), Centro Universitário de Araraquara, Araraquara, 14801-340 São Paulo, Brazil. E-mail address: hernane.barud@gmail.com (H.S. Barud).
}

linked by adjacent $\alpha$-1,4-glucan molecules. The cellulose macromolecules folds over each other giving rise to the protofibrills, which successively folds reaching the nanometric scale leading to the nanofibrills (Hirai, Tsuji, \& Horii, 2002; Kondo \& Tomita, 2009; Trovatti, 2013). The chemical structure of BC is the same as the cellulose from plants or algae; however, BC is free of lignin, hemicellulose and pectin. $\mathrm{BC}$ is a natural nanomaterial consisted of a peculiar tridimensional network structure of ribbon-shaped cellulose nanofibrils (3-8 $\mathrm{nm}$ in diameter) (Czaja, Krystynowicz, Bielecki, \& Brown, Jr., 2006) that favor its mechanical properties (Czaja, Romanovicz, \& Brown, 2004).

BC has a high specific surface afforded by the network of nanoscale fibers, surprising absorption capacity and water retention, biodegradability, biocompatibility, non-allergenic, nontoxic features and it is easy moldable (Klemm, Schumann, Udhardt, \& Marsch, 2001, Klemm et al., 2005). BC is used for different purposes, mainly in food industry (dietary fiber and desserts "nata de coco"), textiles, opto-electronic devices, medical devices (surgical tubes, temporary skin substitutes, contact lens), among others 
(Chawla, Bajaj, Survase, \& Singhal, 2009; Klemm, Heublein, Fink, \& Bohn, 2005; Legnani et al., 2008; Pecoraro, Manzani, Messaddeq, \& Ribeiro, 2008; Pinto et al., 2015; Shah \& Brown, 2005).

Gluconacetobacter species produce cellulose membranes at the surface of static culture medium. Under appropriate conditions, the bacteria can convert up to $50 \%$ of the carbon substrate to produce $\mathrm{BC}$. Considering agitated culture, microbial growth is more intense due to the larger oxygen supply in the culture medium (Ross, Mayer, \& Benziman, 1991). Spheres or elongated agglomerates of fibers are formed instead. Despite promising expectations for BC, until now, large-scale production of this material requires more investigation.

In nature, the microorganism grows at the surface of rotting fruits, from where they get energy and the nutrients needed for reproduction. The synthesis of the cellulose mats, which is wove on the top of the colonies, has the function of protection against dehydration, sunlight, competitors and strategically, preservation of the nutrient sources. Consequently, BC produced from different bacteria results in different BC properties, such a yield and/or morphology.

Bacterial cellulose is easily found in homemade culture medium in Asia because its ethnopharmaceutical history. Kombucha tea is the name of the green tea inoculated with a consortium of acetogenic bacteria, in which one of the microorganisms is a cellulose producer. This microorganism easily grows with low amounts of nitrogen source which in Kombucha tea is around $0.7 \mathrm{~g} / \mathrm{L}$ (Nguyen, Flanagan, Gidley, \& Dykes, 2008). Coconut water is another food source able to produce cellulose. Although coconut water is a poor nutrient source, it produced high yield BC (Aragon, 2000). Several species of cellulose producing microorganisms have been isolated from food sources such as "nata de coco" and Kombucha tea.

Examples of classical cellulose producing microorganisms are G. xylinum and G. hansenii. Moreover, in the last years, G. sacchari from Kombucha tea (Trovatti et al., 2011) and G. persimmonensis KJ145 (KCTC 10175BP) from matured persimmon vinegar (OhSeuk, Se-Young, \& Young-Jin, 2002) have been identified. Recently, dos Santos and coworkers (dos Santos et al., 2014) isolated Komagataeibacter rhaeticus specie as a new cellulose producer.

The goal of this research work is a comparative study on production and characterization of bacterial cellulose biosynthesized by novel $K$. rhaeticus bacterium. Moreover, a G. xylinum (ATCC23760) bacterium was used for comparing the results of yield and BC membrane features, since G. xylinum is well known as cellulose producing bacterium and was characterized by numerous authors (Chawla et al., 2009; Li et al., 2015; Pecoraro et al., 2008). Different characterization techniques were employed to study physicochemical, morphological and mechanical properties of BC membranes.

\section{Materials and methods}

\subsection{Isolation and identification of Komagataeibacter rhaeticus bacterium}

Kombucha tea was prepared using $20 \mathrm{~g}$ of green tea, $40 \mathrm{~g}$ of sucrose and $1 \mathrm{~L}$ of tap water. $100 \mathrm{~mL}$ of Kombucha starter culture obtained from Indo Kombucha was added to the tea. The culture was incubated at $30^{\circ} \mathrm{C}$ for 10 days. The cellulose membrane was vigorously shaken in the tea. $1 \mathrm{~mL}$ of the suspension was withdrawn from the tea and added to a test tube with $9 \mathrm{~mL}$ of $0.9 \mathrm{wt} \%$ $\mathrm{NaCl}$ sterile solution and a serial dilution was performed with ten tubes. Aliquots of each dilution were plated on Petri dishes with solid Hestrin and Schramm (HS) culture medium. The plates were incubated at $30^{\circ} \mathrm{C}$ for 5 days. The grown colonies were isolated according to its morphological features, seeded in solid HS medium and incubated at $30^{\circ} \mathrm{C}$ for $48 \mathrm{~h}$. Then, in order to evaluate the cellulose formation at the top of the liquid, one isolated colony from

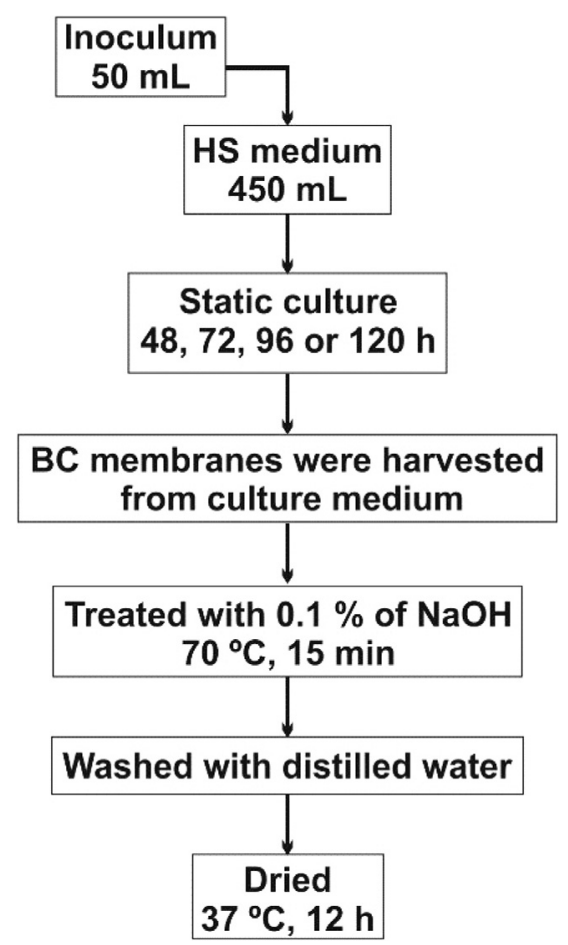

Scheme 1. Biosynthesis and purification of bacterial cellulose.

each Petri dish was transferred to test tubes with HS broth and incubated aerobically at $30^{\circ} \mathrm{C}$ for 5 days. The cellulose producer was then identified and used for cellulose production and characterization. The microorganism $K$. rhaeticus was labeled as AF-1. This genome was sequenced on the Illumina HiSeq2000 system, generating 44,413,164 paired-end reads of $100 \mathrm{bp}$ (insert size, $250 \mathrm{bp}$ ) (dos Santos et al., 2014).

\subsection{Gluconacetobacter xylinus}

G. xylinus ATCC 23760 was supplied by Fundação André Tosello Pesquisa e Desenvolvimento, Brazil.

\subsection{Production and purification of $B C$ membranes}

The production of the $\mathrm{BC}$ membranes was carried out by cultivation of AF- 1 and ATCC-23760 strains in static culture liquid medium (HS), composed by $50 \mathrm{~g} / \mathrm{L}$ glucose, $4 \mathrm{~g} / \mathrm{L}$ of yeast extract, $0.73 \mathrm{~g} / \mathrm{L}$ of $\mathrm{MgSO}_{4} \cdot 7 \mathrm{H}_{2} \mathrm{O}, 2 \mathrm{~g} / \mathrm{L} \mathrm{KH}_{2} \mathrm{PO}_{4}, 20 \mathrm{~g} / \mathrm{L}$ ethanol and distilled water, $1000 \mathrm{~mL}$, properly sterilized. Ethanol was sterilized by filtration and added to the cold media. The microorganisms were incubated statically in four plastic trays $\left(25 \times 36 \mathrm{~cm}^{2}\right)$, at $28^{\circ} \mathrm{C}$. The trays were covered with a sheet paper to avoid the deposition of powder from the environment. The cultivation process was carried out under aseptic conditions. The volume of culture media was $450 \mathrm{~mL}$ and the inoculum volume was $50 \mathrm{~mL}$ for each tray. The pre-inoculum was prepared in HS liquid medium $(100 \mathrm{~mL})$ from one isolated colony, which was used to inoculate the trays after $24 \mathrm{~h}$ of incubation. BC membranes were cultivated for $48,72,96$ and $120 \mathrm{~h}$.

BC membranes of AF-1 (K-BC) and ATCC-23760 (G-BC) were treated with $0.1 \%$ solution of $\mathrm{NaOH}$ at $70^{\circ} \mathrm{C}$ for $15 \mathrm{~min}$, and then carefully washed in distilled water until neutral $\mathrm{pH}$.

Bacterial cellulose biosynthesis and purification protocol was summarized in Scheme 1. 


\subsection{Kinetics studies}

To obtain mass and thickness data the membranes were cut in small squares $\left(10 \mathrm{~cm}^{2}\right)$. Then, dried at $37^{\circ} \mathrm{C}$ for $12 \mathrm{~h}$. Thickness and weight measurements were performed before and after drying process using a digital caliper and a digital scale. The thickness was measured in 5 different positions and values were averaged.

\subsection{Water holding capacity}

The wet BC membranes $\left(10 \mathrm{~cm}^{2}\right)$ cultivated at different growth times, 48, 72, 96 and 120 h, were weighted. Subsequently, wet BC sheets were dried under vacuum at $37^{\circ} \mathrm{C}$ for $12 \mathrm{~h}$ in an oven. Five samples of each growth time were analyzed.

The water holding capacity (WHC) was calculated by the following formula (Shezad, Khan, Khanb, \& Park, 2010):

$$
\begin{aligned}
& \text { WHC = mass of water removed during drying }(\mathrm{g}) / \\
& \text { dry weight of cellulose }(\mathrm{g})
\end{aligned}
$$

\subsection{BC membrane characterization}

UV-vis transmission spectra were collected in a Varian-CARY 500 spectrophotometer in the range of $800-300 \mathrm{~nm}$ wavelength.

Fourier Transform Infrared (FTIR) spectra were acquired using a Nicolet Nexus Spectra equipped with a Golden Gate single reflection diamond ATR accessory. Spectra were collected, with a $2 \mathrm{~cm}^{-1}$ resolution and 32 scans, in the wavenumber region of $4000-600 \mathrm{~cm}^{-1}$.

The thermogravimetric curves of the samples were recorded by a TA SDT 2960 from TA Instruments Co.All samples were heated in alumina pans from $25^{\circ} \mathrm{C}$ to $600^{\circ} \mathrm{C}$ temperature range under nitrogen atmosphere (flow rate of $100 \mathrm{~mL} \mathrm{~min}^{-1}$ ) at a heating rate of $10^{\circ} \mathrm{Cmin}^{-1}$.

X-ray diffraction patterns were obtained with a Siemens Kristalloflex diffractometer using nickel filtered $\mathrm{Cu}$ Ka radiation, a step size of 0.021 and a step time of $3 \mathrm{~s}$, from 51 to 501 ( $2 \theta$ angle).

The morphology of K-BC and G-BC membranes was studied using an atomic force microscopy (AFM) and scanning electron microscopy (SEM).

AFM images were obtained by operating in tapping mode with a scanning probe microscope Dimension ICON from Bruker equipped with an integrated silicon tip/cantilever having a resonance frequency of $300 \mathrm{kHz}$. Scan rates ranged from 0.7 to $1.2 \mathrm{~Hz} / \mathrm{s}$. Taking into account that obtained height and phase AFM images were very similar only AFM phase images are shown here. PeakForce quantitative nanomechanical property mapping (PeakForce QNM) was used to study nanomechanical properties of K-BC and G-BC membranes using the same Dimension Icon microscope from Bruker. Measurements were carried out in PeakForce mode under ambient conditions. A silicon tip with nominal radius of $10 \mathrm{~nm}$, cantilever length of $125 \mu \mathrm{m}$, and resonance frequency of $150 \mathrm{kHz}$ was used. The measurements were performed with a calibrated optical sensitivity. The exact spring constant of the tip was calculated using the Thermal Tune option and a defined tip radius was adjusted using PS as standard.

Scanning electron microscope (SEM) images were taken on a JEOL JSM-7000 F instrument operated at $2 \mathrm{kV}$. The samples were coated with carbon.

The mechanical properties of K-BC and G-BC membranes were measured at room temperature using with a Dynamic Mechanical Analyzer (DMA) 2980 (TA Instruments) equipped with a tension clamp. Specimens of $6 \mathrm{~mm}$ length and $3 \mathrm{~mm}$ width and thickness values range from 50 to $150 \mu \mathrm{m}$. A preload force of $0.01 \mathrm{~N}$ was used and the force ramp $8 \mathrm{~N} / \mathrm{m}$ until the rupture of sample. The device was previous calibrated and a total of 10 measurements for each sample were made in order to ensure the reproducibility of the results.

\section{Results and discussion}

The wet weight, yield,thickness and the water holding capacity of the membranes, according to the growth time, are showed in Fig. 1a-d respectively, for both, K-BC and G-BC membranes. At the same growth times, wet weight of biosynthesized $\mathrm{BC}$ membranes was very similar for both strains (Fig. 1a). Moreover, as was expected, growth studies reveal an increase of yield (Fig. 1b) and thickness(Fig. 1c) an increase of yield and thickness as a result of increasing the cultivation time. Here, it should be noted that for $96 \mathrm{~h}$ and $120 \mathrm{~h}$ growth times, the yield and thickness of K-BC increased almost two times if compared with results obtained for G-BC.

In a deeply study, one can observed an interesting relation between thickness of dried membranes and wet weight for this two samples. For $96 \mathrm{~h}$ and $120 \mathrm{~h}$ growth times, K. rhaeticus bacterium synthesized thicker membrane than G. xylinum, however the wet weight was similar for both $\mathrm{K}-\mathrm{BC}$ and $\mathrm{G}-\mathrm{BC}$ synthesized membrane. Taking these results into account, it can be concluded that $K$. rhaeticus bacterium was able to synthesize more dense and less porous $\mathrm{BC}$ membrane.Thus, make these materials interesting for a broad field of applications reaching from biomedical (wound healing, scaffolds for tissue engineering or substrates for cell seeding) to construction (thermal or acoustic insulation or shock absorption) purposes.

With respect to the yield of dried BC membranes (Fig. 1b), at short growth times yields are similar for both samples. On the contrary, for longer growth times, K-BC production was 50\% higher if compared to G-BC production, $\sim 6.7 \mathrm{~g} / \mathrm{L}$ or $0.07 \mathrm{~g} / \mathrm{L} / \mathrm{h}$ for $\mathrm{K}-\mathrm{BC}$ and $\sim 3.4 \mathrm{~g} / \mathrm{L}$ or $0.035 \mathrm{~g} / \mathrm{L} / \mathrm{h}$ for $\mathrm{G}-\mathrm{BC}$ at $96 \mathrm{~h}$ growth time. Some results found in literature exhibited similar or higher yields, however, using reactors and culture medium specific for $\mathrm{BC}$ production. For instance, the production of $\mathrm{BC}$ using a shaking flask reactor reached a yield of $0.08 \mathrm{~g} / \mathrm{L} / \mathrm{h}$ (Son, Heo, Kim, \& Lee, 2001), in a stirred tank with continuous culture the production was $0.95 \mathrm{~g} / \mathrm{L} / \mathrm{h}$ (Naritomi, Kouda, Yano, \& Yoshinaga, 1998), using a rotating disk $0.02 \mathrm{~g} / \mathrm{L} / \mathrm{h}$ (Krystynowicz et al., 2002), in an airlift the yield was $0.2 \mathrm{~g} / \mathrm{L} / \mathrm{h}$ (Chao, Ishida, Sugano, \& Shoda, 2000) and using a fed bath it was $0.11 \mathrm{~g} / \mathrm{L} / \mathrm{h}$ (Bae \& Shoda, 2004). Comparing the result obtained for BC synthesized by $K$. rhaeticus bacterium, $\sim 0.07 \mathrm{~g} / \mathrm{L} / \mathrm{h}$, with the literature, the production of K-BC was surprisingly high taking in to account that the culture media used in this work is a poor source of nutrients and the production process was a simple tray, with no aeration, fed bath or continuous cultivation.

Fig. 1d shows that all investigated K-BC membranes possessed lower water content than corresponding membrane of G-BC. This fact indicates that $K$. rhaeticus bacterium produces less porous $\mathrm{BC}$ membrane comparing with $G$. xylinus produced $B C$ membrane. This fact was in agreement with results related to thickness and wet weight in function of growth time.

The effect of the thickness on the transparency of dried K-BC membrane can be visualized in Fig. 2. Increasing cultivation time increased the mass of the membranes and proportionally also the thickness. Thus, for longer cultivation times obtained membranes are thicker than for short cultivation times and consequently more opaque as can be observe in UV-vis results. Taking this into account one can conclude that light transmission decrease when the thickness of the membrane increases.

FTIR spectrum of biosynthesized G-BCand K-BC membranes are shown in Fig. 3. G-BC and K-BC spectrum are similar, indicating that cellulose has the same chemical structure regardless the bacterium used for the production. In both FTIR spectra all the typ- 

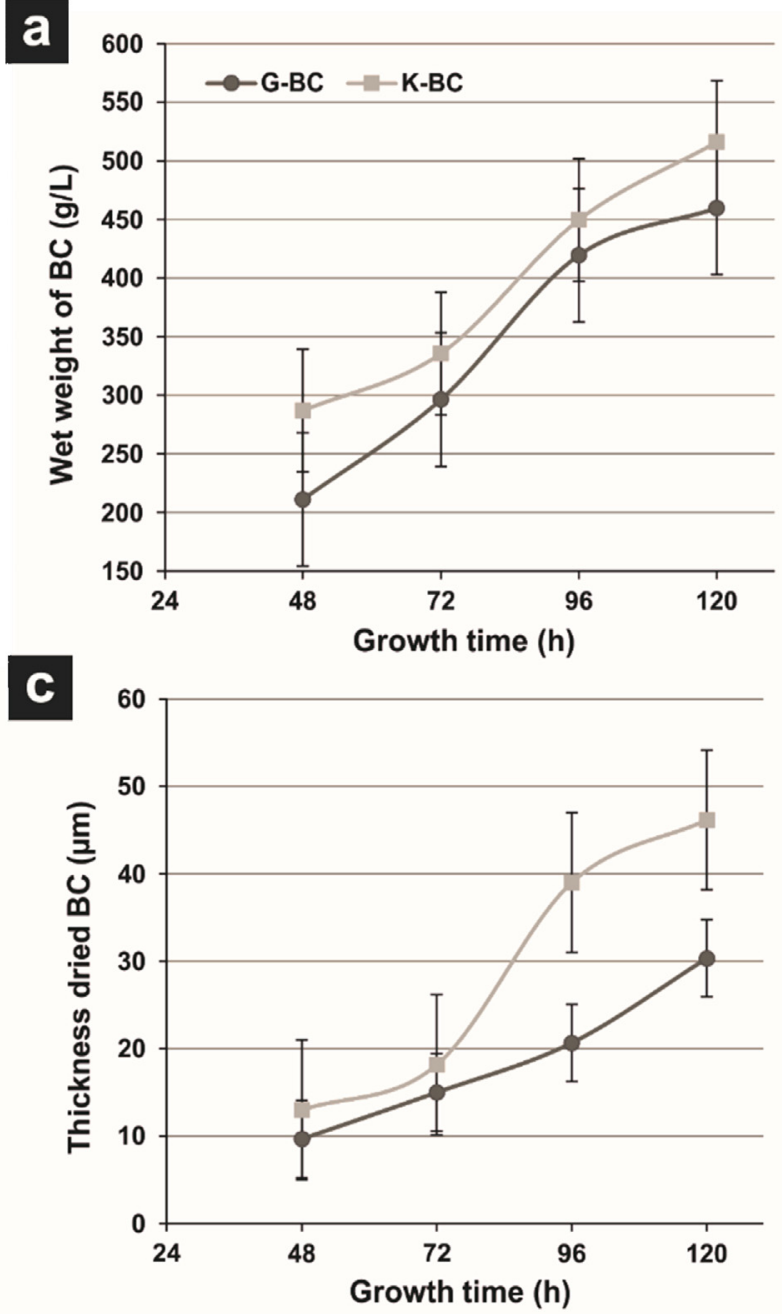

b

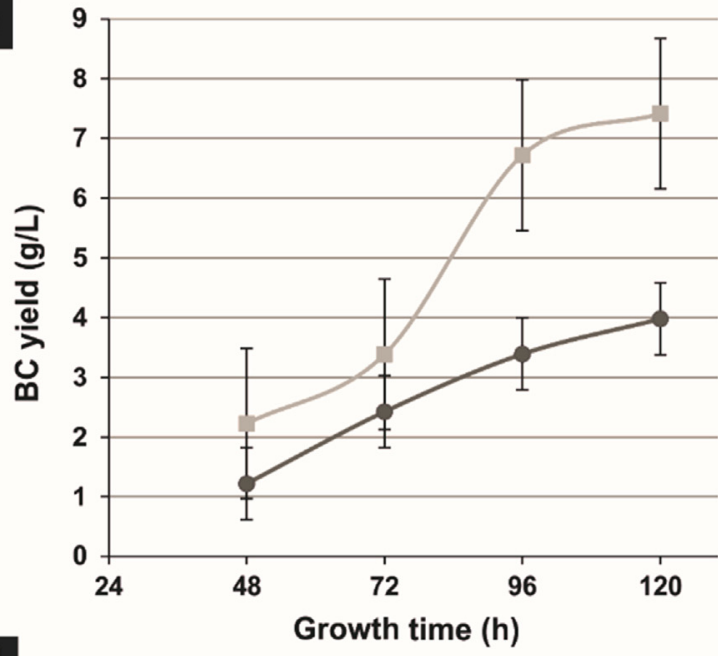

d

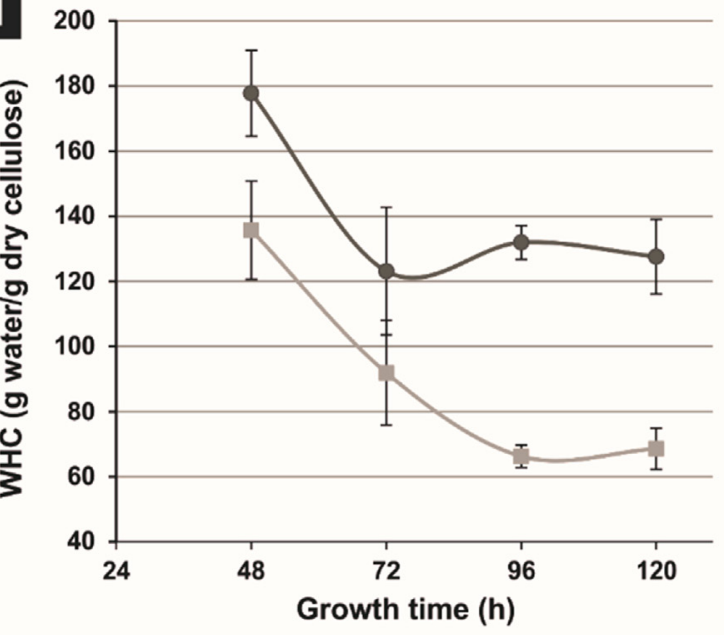

Fig. 1. (a)Wet BC membrane weight, (b) dry BC yield (c) wet BC membrane thickness and (d) and water holding capacity (WHC) for G-BC and K-BC.

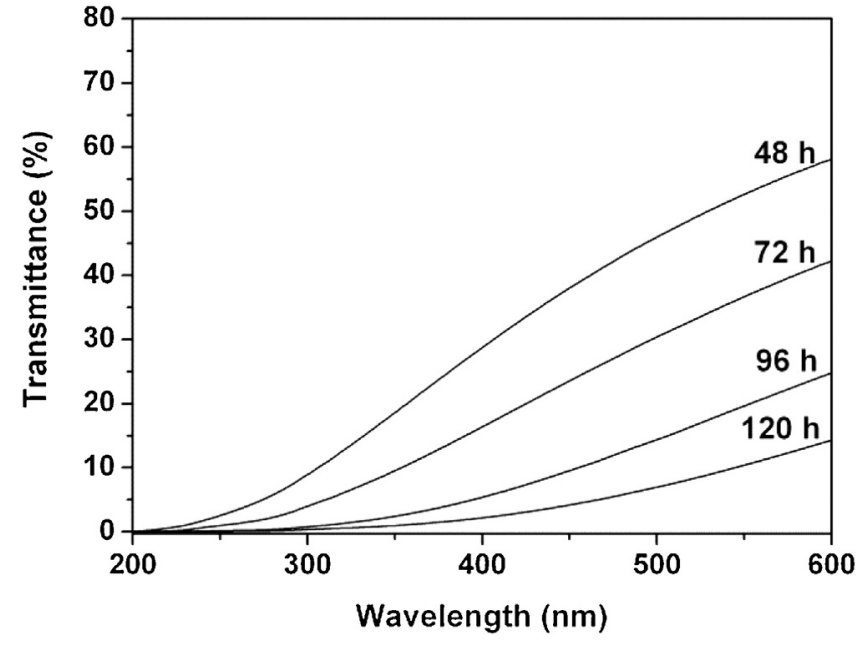

Fig. 2. UV-vis spectroscopy of K-BC membrane after different cultivation times.

ical bands of the bacterial cellulose were detected (Moharram \& Mahmoud, 2008; Movasaghi, Rehman, \& Rehman, 2008). Thus, the band at $3345 \mathrm{~cm}^{-1}(\mathrm{O}-\mathrm{H}$ stretch of cellulose type I) (Moharram \& Mahmoud, 2008) and the band at $3240 \mathrm{~cm}^{-1}$ (stretching of hydrogen bonded O-H) (Focher et al., 2001) can be clearly observed.

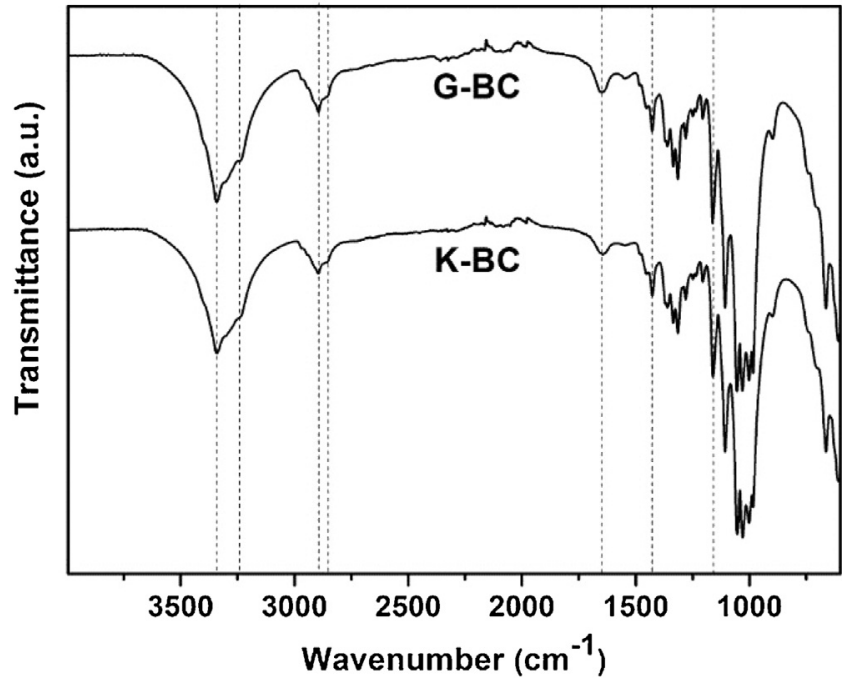

Fig. 3. FTIR of biosynthesized BC membranes.

Here, it should be noted that the bands at $3488 \mathrm{~cm}^{-1}$ and $3447 \mathrm{~cm}^{-1}$ assigned for $-\mathrm{OH}$ stretching intramolecular hydrogen bonding as typical for cellulose II (Moharram \& Mahmoud, 2008) are not found in those spectra. Moreover, band assigned to $\mathrm{CH}$ stretching of $\mathrm{CH}_{2}$ 

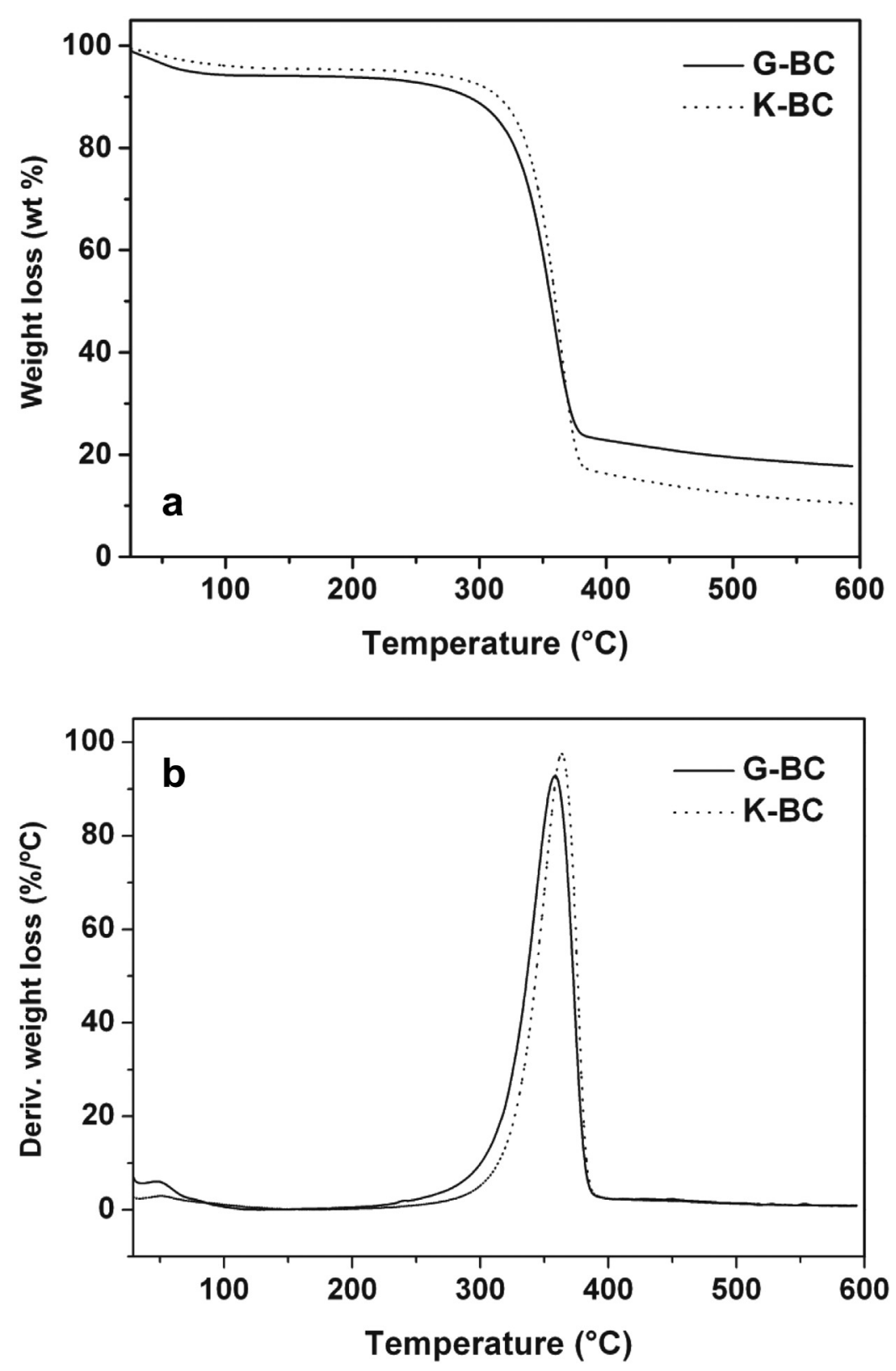

Fig. 4. (a) Thermogravimetric and (b) differential thermal analysis curves of biosynthesized BC membranes.

groups at $2893 \mathrm{~cm}^{-1}$, the band corresponding to $\mathrm{CH}_{2}$ asymmetric stretching at $2854 \mathrm{~cm}^{-1}$ (Oh et al., 2005) and the band at $1650 \mathrm{~cm}^{-1}$ assigned to water absorbed (Moharram \& Mahmoud, 2008) can also be detected. Finally, the spectra showed the characteristic signals of cellulose I, with strong bands at $1425 \mathrm{~cm}^{-1}$ and at $1160 \mathrm{~cm}^{-1}$ assigned to $\mathrm{CH}_{2}$ symmetric bending (Oh et al., 2005) and to $\mathrm{C}-\mathrm{O}-\mathrm{C}$ asymmetric stretching (Movasaghi et al., 2008), respectively.

Fig. 4 shows the TG/DTG curves for G-BC and K-BC membranes. As expected, both thermograms show great similarity. TG/DTG curves show two main weight losses. The first weight loss occurs from room temperature to $200^{\circ} \mathrm{C}$ and is attributed to membrane dehydratation or evaporation of the surface water. This weight loss corresponds to $\sim 5.0 \%$ of the total mass. The second weight loss begins at $\sim 280^{\circ} \mathrm{C}$ for both membranes and possess a maximum decomposition temperature $\left(\mathrm{T}_{\text {onset }}\right)$ at $358^{\circ} \mathrm{C}$ and $361^{\circ} \mathrm{C}$ for $\mathrm{G}$ $\mathrm{BC}$ and $\mathrm{K}-\mathrm{BC}$ membranes, respectively. This weight loss represents $80 \mathrm{wt} \%$ of the total mass of the $\mathrm{BC}$ membrane and is attributed to thermal degradation, like depolymerization and decomposition of dehydrocellulose into gases (water, carbon monoxide and carbon dioxide) (Barud, 2007)

XRD patterns for G-BC and K-BC membranes are shown in Fig. 5. Broad diffraction peaks are observed at $14.3^{\circ}$ and $22.5^{\circ}$ for both samples. Diffraction peaks are assigned to the cellulose I $\alpha$ and I $\beta$ phases $\left(100 \mathrm{I} \alpha, 110 \mathrm{I} \beta\right.$ and $010 \mathrm{I} \beta$ planes at $14.3^{\circ}$ and $110 \mathrm{I} \alpha$ and $200 \mathrm{I} \beta$ at $22.5^{\circ}$ ). These peaks are assigned to the characteristic interplanar spacing of native cellulose type I (Kim, Kim, Wee, Park, \& Ryu, 2006). The crystallinity index of the BC membranes was calculated from according to the Segal method (1).

$\mathrm{CrI}=\frac{\mathrm{I}_{002}-\mathrm{I}_{\mathrm{am}}}{\mathrm{I}_{002}} \times 100$

in Seagal equation, CrI expresses the relative degree of crystallinity, $\mathrm{I}_{002}$ is the maximum intensity (in arbitrary units) of the 002 lattice diffraction and $\mathrm{I}_{\mathrm{am}}$ is the intensity of diffraction in the same 


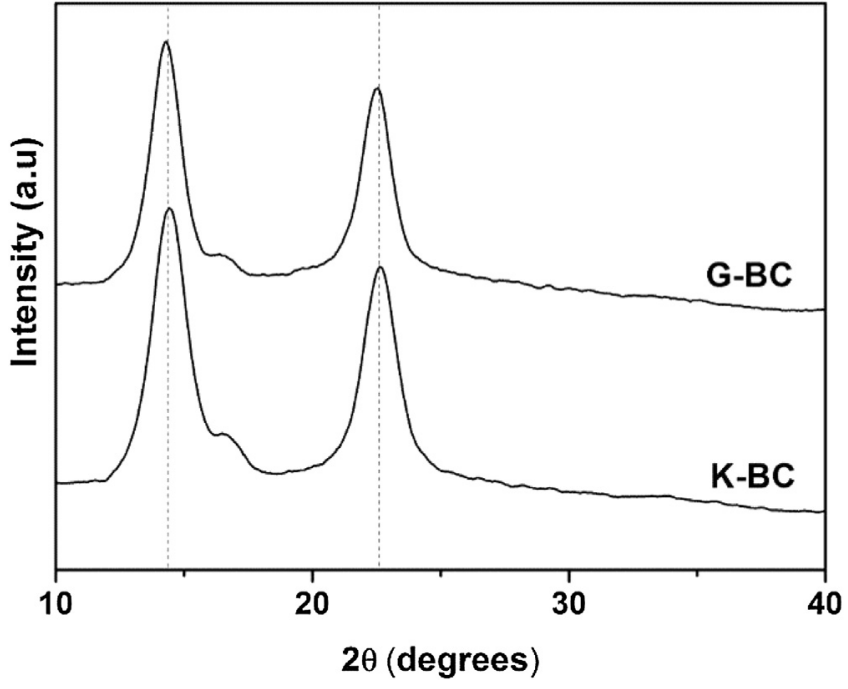

Fig. 5. X-ray diffraction patterns of biosynthesized BC membranes.

units at $2 \theta=18^{\circ}$. CrI value was $85 \%$ and $83 \%$ for G-BC and $\mathrm{K}-\mathrm{BC}$, respectively. These values are similar to others reported from the literature (Trovatti et al., 2011)

Fig. 6 shows SEM micrographs of G-BC and K-BC dried membranes. Here, SEM micrographs reveal a three-dimensional ribbon-like nanofibril structure with a fiber diameter around $50 \mathrm{~nm}$ for both membranes. The micrographs evidenced a more dense structure of the membrane produced by K-BC when compared to $\mathrm{G}-\mathrm{BC}$, totally in agreement with the data discussed in Fig. 1.

Atomic force microscopy (AFM) was used to study the morphological properties of the $\mathrm{G}-\mathrm{BC}$ and $\mathrm{K}-\mathrm{BC}$ membranes. As clearly observed in Fig. 7 both $\mathrm{BC}$ membranes, biosynthesized by K-BCand G-BC, showed typical interconnected tridimensional nanofibers network. The average size of the nanofibers was around $150 \pm 50 \mathrm{~nm}$ and $100 \pm 25 \mathrm{~nm}$ for G-BC and K-BC membranes, respectively. Here it should be pointed out that each nanofibers consists of 2-5 fibrils with the average size lower than $35 \mathrm{~nm}$ connected between each other and in some occasion twisted along the axis as a consequence of their longitude. The structural properties of detected by AFM are in good agreement with structural properties described above taken into account corresponding SEM images.

Quantitative nanomechanical properties (QNM) of G-BC and KBC membranes were investigated using AFM in PeakForce mode. AFM height, adhesion and elastic modulus images of biosynthesized BC membranes are showed in Fig. 8. As clearly observed from AFM height images of both G-BC and K-BC membranes (Fig. 8aI and bI) the tridimensional nanofibers network have similar roughness, being the average roughness ( $\mathrm{Ra}$ ) equal to 22 and $18 \mathrm{~nm}$ for $\mathrm{G}-\mathrm{BC}$ and K-BC membranes, respectively.

The AFM adhesion images indicated that the adhesion depended slightly on the type of the bacteria used for the biosynthesis of $\mathrm{BC}$ membrane. In the case of $\mathrm{K}-\mathrm{BC}$ membrane the adhesion varied from 8 to $20 \mathrm{nN}$ whereas for G-BC membrane the adhesion changed between 5 and $15 \mathrm{nN}$ (Fig. 8 aII and bII). In both cases, the variation is regularly distributed along the investigated surface. This behavior indicates the homogeneity of the nanofibers which build the interconnected tridimensional network. Moreover, QNM properties indicated that the elastic modulus of the $\mathrm{BC}$ membrane fabricated using $\mathrm{K}-\mathrm{BC}$ is more than two times higher if compare with elastic modulus of the $B C$ membrane fabricated using $\mathrm{G}-\mathrm{BC}$. Similarly to PeakForce QNM adhesion image, PeakForce QNM elastic modulus images indicated homogeneous distribution of elastic modulus on whole investigated surface being the average elastic modulus corresponds to $3 \mu \mathrm{m} \times 3 \mu \mathrm{m}$ mapped area $1.2 \mathrm{GPa}$ and
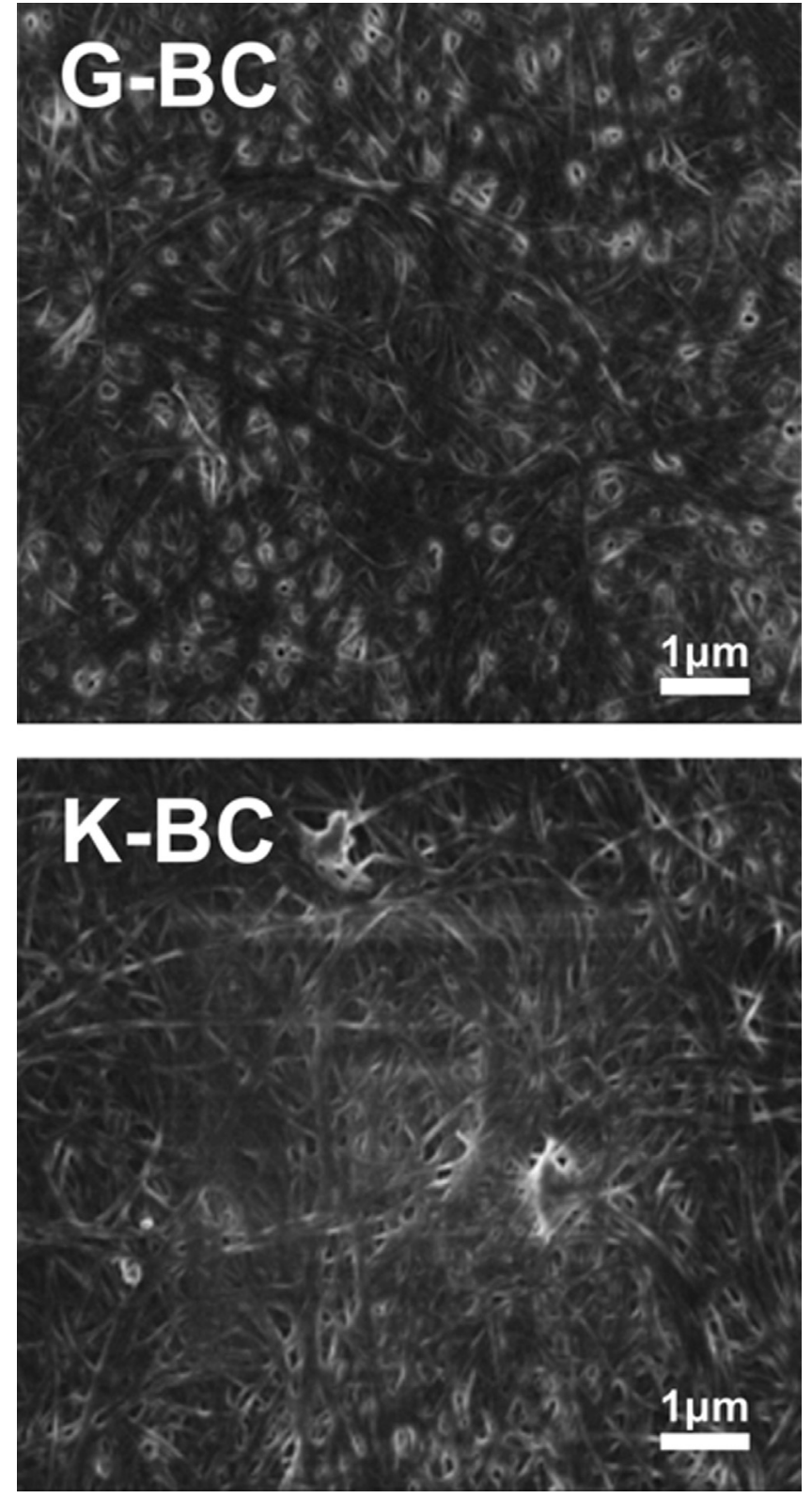

Fig. 6. SEM images of biosynthesized BC membranes.

2.8 GPa for G-BC and K-BC membranes, respectively (Fig. 8aIII and bIII).

The mechanical properties can be correlated to the morphological features of the membranes. K-BC showed higher mechanical properties when compared to $\mathrm{G}-\mathrm{BC}$, indicating the positive effect of low diameter $B C$ nanofibers in mechanical properties of the membranes. as expected, once their nanofiber have lower diameter. The degree of crystallinity normally increases the mechanical properties of the materials, but here it was possible to observe no influence of the crystallinity, since both samples showed similar features (Fig. 5), suggesting the increase in mechanical properties was influenced only by the morphology of the nanofibers.

In order to study mechanical properties of biosynthesized BC membranes on the macroscopic scale DMA measurements in static conditions were performed. The values of the tensile strain, deformation and Young modulus of G-BC and K-BC membranes are listed in Table 1 . As can be observed the tensile strain is slightly higher in the case of $\mathrm{K}-\mathrm{BC}$ membrane if compare to G-BC one and the same behavior was also observed for the deformation of both, being 

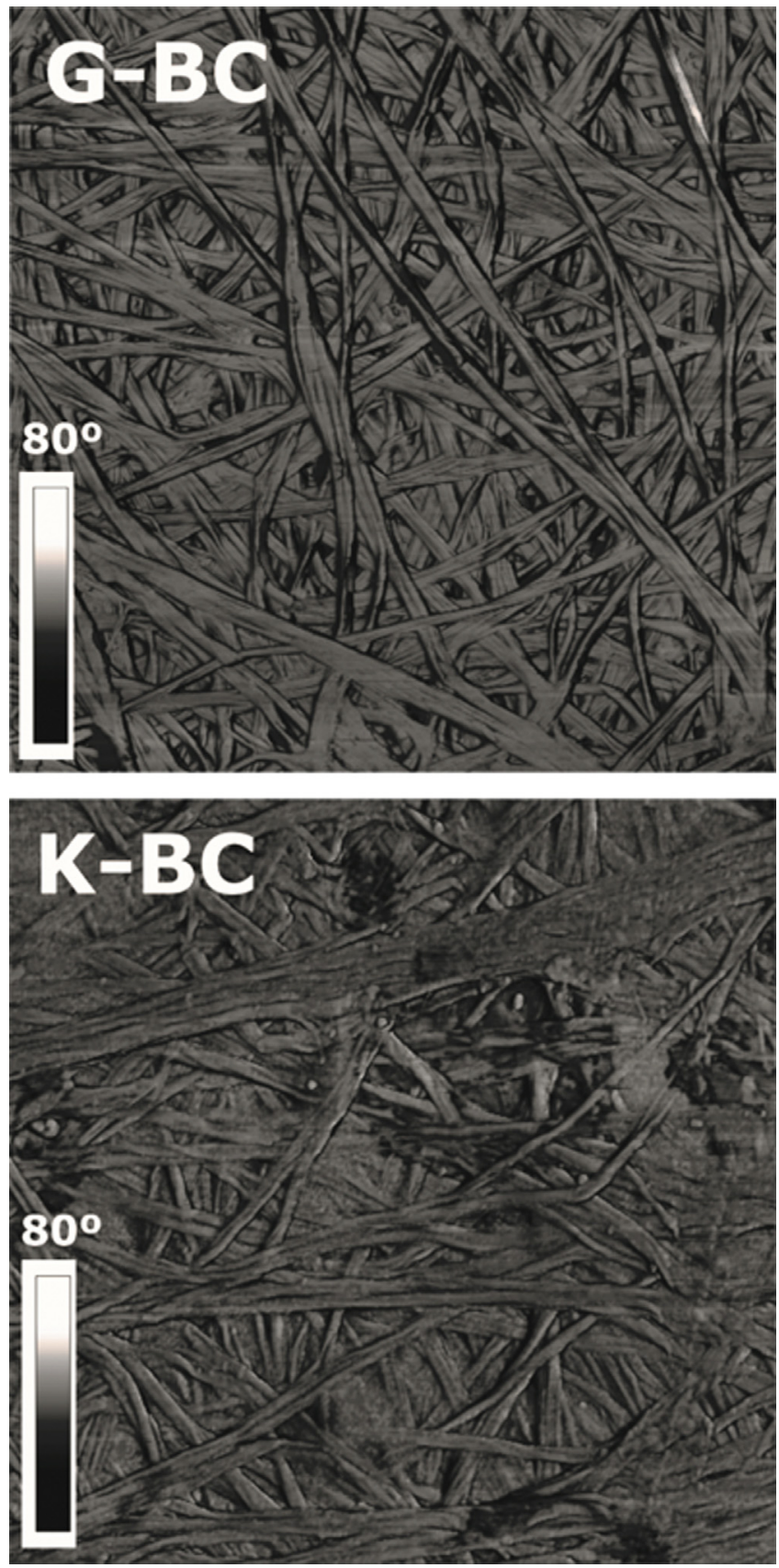

Fig. 7. AFM phase images $(3 \mu \mathrm{m} \times 3 \mu \mathrm{m})$ of biosynthesized $\mathrm{BC}$ membranes.

Table 1

Tensile strain, deformation and Young modulus of G-BC and K-BC membranes.

\begin{tabular}{llll}
\hline Sample & Tensile stress (MPa) & Deformation (\%) & Young's modulus (GPa) \\
\hline G-BC & $41.5 \pm 4$ & $2.5 \pm 0.3$ & $1.5 \pm 0.2$ \\
K-BC & $46.9 \pm 3$ & $1.5 \pm 0.3$ & $3.2 \pm 0.3$ \\
\hline
\end{tabular}

$2.5 \%$ for $\mathrm{G}-\mathrm{BC}$ and $1.5 \%$ for $\mathrm{K}-\mathrm{BC}$. The main difference was observed for Young Modulus values. The Young modulus of the K-BC membrane is more than two times higher than the Young modulus of the G-BC being 3.2 GPa for K-BC and 1.5 GPa for G-BC. The DMA results are in good agreement with the results obtained using quantitative nanomechanical properties reached by AFM operated in PeackForce mode.

\section{Conclusions}

Komagataeibacter rhaeticus bacterium was able to biosynthesized BC membranes with production parameters similar to Gluconacetobacter xylinum. For $96 \mathrm{~h}$ cultivation time, BC membrane production using $\mathrm{K}$. rhaeticus was $50 \%$ higher if compared to $G$. xylinum production. Moreover, K. rhaeticus bacterium produces less porous tridimensional network BC membrane. Physicochemical and morphological characterization revealed that $\mathrm{K}-\mathrm{BC}$ membrane exhibited similar properties to G-BC membranes. Mechanical properties at nanoscale, measured by QNM, and at macroscale, measured by DMA, were in good agreement. Finally, obtained results proved that $K$. rhaeticus bacterium can be used as a viable alternative for cellulose production. 

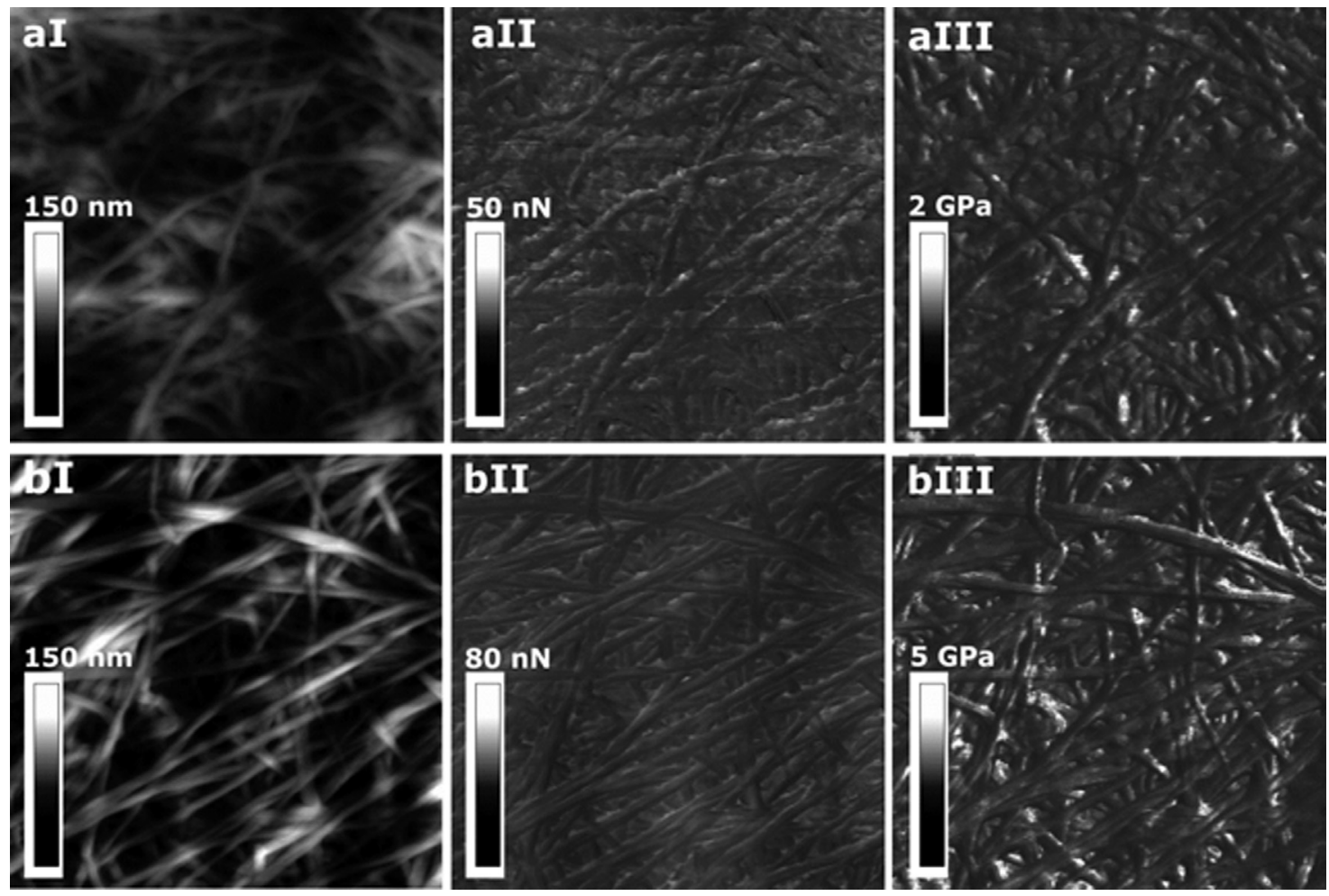

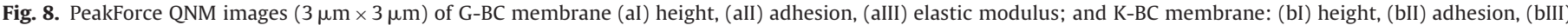
elastic modulus.

\section{Acknowledgements}

FAPESP for financial support process 13/04948-9 linked to aid 11/51725-0. Financial support from Spanish Ministry of Economy and Competitiveness in the frame ofMAT2015-66149-P project. J.G. acknowledges UPV/EHU for Postdoctoral Fellow (ESDOC13/059). Moreover, we are grateful to the 'Macrobehavior-MesostructureNanotechnology' SGIker unit of the UPV/EHU.

\section{References}

Aragon, T. (2000). Coconut Program Area Research Planning and Prioritization, Philipine Institute for Development studies. Makati City: Philipines PIDS Discussion Paper Series. http://dirp4.pids.gov.p/ris/dps/pidsdps0031.pdf

Bae, S., \& Shoda, M. (2004). Bacterial cellulose production by fedbatch fermentation in molasses medium. Biotechnology Progress, 20,1366-1371.

Barud, H. S.-G. (2007). Thermal characterization of bacterial cellulose-phosphate composite membranes. Journal of Thermal Analysis and Calorimetry, 87, $815-818$.

Brown, A. J. (1886). On an acetic ferment which forms cellulose. Journal of the Chemical Society, Transactions, 49, 432-439.

Chao, Y., Ishida, T., Sugano, Y., \& Shoda, M. (2000). Bacterial cellulose production by Acetobacter xylinum in a 50-L internal-loop airlift reactor. Biotechnology and Bioengineering, 68, 345-352.

Chawla, P. R., Bajaj, I. B., Survase, S. A., \& Singhal, R. S. (2009). Microbial cellulose: fermentative production and applications. Food Technology and Biotechnology, 47, 107-124

Czaja, W., Romanovicz, D., \& Brown, R. M., Jr. (2004). Structural investigations of microbial cellulose produced in stationary and agitated culture. Cellulose, 11, 403-411.

Czaja, W., Krystynowicz, A., Bielecki, S., \& Brown, R. M., Jr. (2006). Microbial cellulose-the natural power to heal wounds. Biomaterials, 27, 145-151.

dos Santos, R. A. C., Berretta, A. A., Barud, H. S., Ribeiro, S. J. L., García, L. N. G., Zucchi, T. D., et al. (2014). Draft genome sequence of Komagataeibacter rhaticus strain AF-1 a high producer of cellulose, isolated from Kombucha tea. Genome Announcements, 2, 1-2.

Focher, B., Palma, M. T., Canetti, M., Torri, G., Cosentino, C., \& Gastaldi, G. (2001) Structural differences between non-wood plant celluloses: evidence from solid state NMR, vibrational spectroscopy and X-ray diffractometry. Industrial Crops and Products, 13, 193-208.
Hestrin, S., \& Schramm, M. (1954). Synthesis of cellulose by Acetobacterxylinum. II. Preparation of freeze-dried cells capable of polymerizing glucose to cellulose. Biochemical Journal, 58, 345-352.

Hirai, A., Tsuji, M., \& Horii, F. (2002). Study of band-like cellulose assemblies produced by Acetobacter xylinum at $4^{\circ} \mathrm{C}$. Cellulose, 9, 105-113.

Kim, S.-Y., Kim, J.-N., Wee, Y.-J., Park, D.-H., \& Ryu, H.-W. (2006). Production of bacterial cellulose by Gluconacetobacter sp. RKY5 isolated from persimmon vinegar. Applied Biochemistry and Biotechnology, 121-124.

Klemm, D., Schumann, D., Udhardt, U., \& Marsch, S. (2001). Bacterial synthetized cellulose-artificial blood vessels for microsurgery. Progress in Polymer Science 26, 1561-1603.

Klemm, D., Heublein, B., Fink, H.-P., \& Bohn, A. (2005). Cellulose: fascinating biopolymer and sustainable raw material. Angewandte Chemie International Edition, 44, 3358-3393.

Kondo, T., \& Tomita, Y. (2009). Influential factors to enhance the moving rate of Acetobacter xylinum due to its nanofiber secretion on oriented templates. Carbohydrate Polymers, 77, 754-759.

Krystynowicz, A., Czaja, W., Wiktorowska-Jezierska, A., Gonçalves-Miskiewicz, M., Turkiewicz, M., \& Bielecki, S. (2002). Factors affecting the yield and properties of bacterial cellulose. Journal of Industrial Microbiology and Biotechnology, 29, 189-195.

Legnani, C., Vilani, C., Calil, V., Barud, H. S., Quirino, W., Achete, C., et al. (2008). Bacterial cellulose membrane as flexible substrate for organic light emitting devices. Thin Solid Films, 517, 1016-1020.

Li, Z., Wang, L., Hua, J., Jia, S., Zhang, J., \& Liu, H. (2015). Production of nano bacterial cellulose from waste water of candied jujube-processing industry using Acetobacter xylinum. Carbohydrate Polymers, 120, 115-119.

Lustri, W. R., Gomes de Oliveira Barud, H., Barud, H. S., Peres, M. F. S., Gutierrez, J., Tercjak, A., et al. (2015). Microbial cellulose-biosynthesis mechanisms and medical applications. In M. Poletto, \& H. L. Ornaghi (Eds.),

Cellulose-fundamental aspects and current trends. InTech. http://dx.doi.org/10. $5772 / 61797$

Moharram, M. A., \& Mahmoud, O. M. (2008). FTIR spectroscopic study of the effect of microwave heating on the transformation of cellulose I into cellulose II during mercerization. Journal of Applied Polymer Science, 107, 30-36.

Movasaghi, Z., Rehman, S., \& Rehman, I. (2008). Fourier transform infrared (FTIR) spectroscopy of biological tissues. Applied Spectroscopy Reviews, 43, 134-179.

Naritomi, T., Kouda, T., Yano, H., \& Yoshinaga, F. (1998). Effect of lactate on bacterial cellulose production from continuous culture. Journal of Fermentation and Bioengineering, 85, 89-95.

Nguyen, V. T., Flanagan, B., Gidley, M. J., \& Dykes, G. A. (2008). Characterizationof cellulose production by a Gluconacetobacter xylinus strain from Kombucha. Current Microbiology, 57, 449-453.

Oh, S. Y., Yoo, D. I., Shin, Y., Kim, H. C., Kim, H. Y., Chung, Y. S., et al. (2005). Crystalline structure analysis of cellulose treated with sodium hydroxide and 
carbon dioxide by means of X-ray diffraction and FTIR spectroscopy. Carbohydrate Research, 340, 2376-2391.

Oh-Seuk, L., Se-Young, J., \& Young-Jin, J. (2002). Culture condition for the production of bacterial cellulose with gluconacetobacter persimmonus K125. 31, 572-577.

Pecoraro, E., Manzani, D., Messaddeq, Y., \& Ribeiro, S. (2008). Bacterial cellulose from Glucanacetobacter xylinus: preparation, properties and appications. In M. N. Belgacem, \& A. Gandini (Eds.), Monomers, polymers and composites from renewable resources (pp. 369-383). Amsterdam: Elsevier Ltd.

Pinto, E. R. P., Barud, H. S., Silva, R. R., Palmieri, M., Polito, W. L., Calil, V. L., et al. (2015). Transparent composites prepared from bacterial cellulose and castor oil based polyurethane as substrates for flexible OLEDs. Journal of Materials Chemistry C, 3, 11581.

Ross, P., Mayer, R., \& Benziman, M. (1991). Cellulose biosynthesis and function in bacteria. Microbiological Reviews, 55, 35-58.

Shah, J., \& Brown, R. M., Jr. (2005). Towards electronic paper displays made from microbial cellulose. Applied Microbiology and Biotechnology, 66, 352-355.

Shezad, O., Khan, S., Khanb, T., \& Park, J. K. (2010). Physicochemical and mechanical characterization of bacterial cellulose produced with an excellent productivity in static conditions using a simple fed-batch cultivation strategy. Carbohydrate Polymers, 82, 173-180.
Shoda, M., \& Sugano, Y. (2005). Recent advances in bacterial cellulose production. Biotechnology and Bioprocess Engineering, 10, 1-8.

Son, H. J., Heo, M. S., Kim, Y. G., \& Lee, S. J. (2001). Optimization of fermentation conditions for the production of bacterial cellulose by a newly isolated Acetobacter sp. A9 in shaking cultures. Biotechnology and Applied Biochemistry, $33,1-5$.

Trovatti, E., Serafim, L. S., Freire, C. S. R., Silvestre, A. J. D., \& Neto, C. P. (2011).

Gluconacetobacter sacchari: an efficient bacterial cellulose cell-factory. Carbohydrate Polymers, 86, 1417-1420.

Trovatti, E., Dufresne, A., Thomas, S., \& Pothen, L. A. (2013). Bacterial cellulose. In A Dufresne, S. Thomas, \& L. A. Pothan (Eds.), Biopolymer nanocomposites: processing, properties, and applications (pp. 339-366). Wiley.

Trovatti, E. (2013). The future of bacterial cellulose and other microbial polysaccharides. Journal of Renewable Materials, 1, 28-41. 